\title{
Stimulus asymmetry in the pigeon's successive matching-to-sample performance
}

\author{
K. R. NELSON and E. A. WASSERMAN \\ University of Iowa, Iowa City, Iowa 52242
}

\begin{abstract}
Two experiments examined the role of color and line-tile keylight stimuli as samples and tests in a symbolic successive matching-to-sample procedure. In Experiment 1, one group of pigeons (Group CL) was given color sample stimuli and line-tilt test stimuli. A second (Group LC) had line-tilt samples and color tests. Group CL mastered the delayed conditional discrimination quite rapidly; however, Group LC showed almost no evidence of learning the problem, even though the retention interval was very short $(1 \mathrm{sec})$. In Experiment 2, a single group of pigeons was given both the color/line and the line/color problems within each training session. Here, even though the birds readily discriminated the colors and the lines, they responded discriminatively to the test stimuli only on color/line trials. Test performance on color/line trials showed a smooth memory gradient from 1 to $16 \mathrm{sec}$; test performance on line/color trials was near chance. Possible reasons for the color/line-tilt asymmetry were considered, including the notion that colors are more memorable for pigeons than line tilts.
\end{abstract}

Stimuli from different sensory dimensions may control behavior to varying degrees (Sutherland \& Mackintosh, 1971). This issue has arisen in recent studies of choice matching-to-sample performance. Carter and Eckerman (1975) reported that the relative ease with which pigeons mastered simultaneous-matching problems depended on the discriminability of the sample and comparison stimuli: The ease of discriminating colors exceeded that of lines of differing orientation. Farthing, Wagner, Gilmour, and Waxman (1977) extended this work to delayed-matching problems. They found that color samples were remembered over longer retention intervals than were line-orientation samples.

The present pair of experiments extended the study of stimulus control over matching-to-sample behavior to the successive matching-to-sample procedure of Konorski (1959; Honig \& Wasserman, 1981). This procedure involves delayed conditional discriminations of the following general form: A sample stimulus is selected to occur from a set of two or more, and, after a delay, a test stimulus is presented, again from a set of two or more. For each sample, only one test stimulus is paired with reinforcement; the remaining test stimuli are never paired with reinforcement after that sample. Performance during the test stimulus provides evidence of memory for the sample; in order to respond discriminatively during the test stimulus in accord with the availability or

This research was supported in part by Grants BNS 75-15905 and 79-14160 from the National Science Foundation to E. A. Wasserman. A portion of the work was submitted in partial fulfillment of the MA degree by Keith R. Nelson. We would also like to thank Mike Grisham and Hanna Mosquera for their helpful assistance. Requests for reprints should be addressed to E. A. Wasserman, Department of Psychology, University of Iowa, Iowa City, Iowa 52242. unavailability of reinforcement, the prior sample must be remembered and the test stimulus must be discriminated.

In the present pair of experiments, symbolic versions of Konorski's (1959) successive-matching procedure were used in which the sample and test stimuli were selected from pairs of colors and line tilts. Experiment 1 investigated performance under the color/line and line/ color problems using independent groups of pigeon subjects. The two problems differed solely in terms of whether colors or lines served as sample or test stimuli: color/line and line/color orders denote the two tasks. Experiment 2 studied performance under two problems using a within-subjects procedure in which both tasks were concurrently scheduled during daily sessions. The prior work of Carter and Werner (1975) and Farthing et al. (1977) suggested that the color/line problem would result in better performance than the line/color problem, due to the reported greater ease of discriminating and remembering color stimuli than line-tilt stimuli.

\section{EXPERIMENT 1}

\section{Method}

Subjects. Eight experimentally naive domestic pigeons were used. They were kept at approximately $80 \%$ of their freefeeding weights. Immediately prior to experimental training, the birds were autoshaped to peck the key stimuli described below.

Apparatus. Four three-key conditioning cubicles were used, although only the center key in each was operative in the present experiment. The key was $2.5 \mathrm{~cm}$ in diameter, was positioned $13 \mathrm{~cm}$ above the grain hopper (BRS/LVE 114-10), and required at least $.15 \mathrm{~N}$ for activation. Key illumination was provided by incandescent bulbs (5.5 V dc, GE 44) in a display projector located behind the clear plastic key. The key could be illuminated by red $(R)$ or green $(G)$ fields or by white lines that bisected the black response key and were oriented vertically (V) or slanted (S) $60 \mathrm{deg}$ from vertical. Each line stimulus was $.2 \mathrm{~cm}$ wide and $2.5 \mathrm{~cm}$ long. Chamber illumination was provided 
by a houselight (5.5 V dc, GE 44 bulb) encased in a metal shield that directed the light toward the ceiling. In each chamber, ventilation was provided by an exhaust fan and white noise was provided through an audio speaker. Experimental events and data collection were controlled by a computer in an adjacent room.

Procedure. Daily sessions comprised 100 trials. A trial began with a $25-\mathrm{sec}$ intertrial interval (ITI). Keypecks made during the last $5 \mathrm{sec}$ prolonged the interval until a minimum of $5 \mathrm{sec}$ elapsed without a keypeck. Following the ITI, one of two equally likely sample stimuli appeared. The first keypeck to the sample after $5 \mathrm{sec}$ terminated the sample stimulus and initiated a 1 -sec retention interval. One of two test stimuli then appeared equiprobably. On positive trials, the first keypeck after $5 \mathrm{sec}$ terminated both the test stimulus and the otherwise illuminated houselight and initiated $2 \mathrm{sec}$ access to the lighted grain hopper. On negative trials, the test stimulus and houselight terminated automatically after $5 \mathrm{sec}$, resulting in $2 \mathrm{sec}$ of blackout. Experimental training comprised 16 daily sessions.

Two groups of four birds received different orders of successively presented keylight stimuli. For Group CL (color/line), $\mathrm{R}$ or $\mathrm{G}$ keylights were the sample stimuli and V or S keylights were the test stimuli; for Group LC (line/color), the order of stimulus presentation was reversed. For half of the birds in each group, $R+V$ (i.e., $R$ followed by $V$ or $V$ followed by $R$ ) and $\mathrm{G}+\mathrm{S}$ stimulus combinations were designated positive trial sequences. For the remaining birds in each group, the positive and negative stimulus combinations were reversed.

Behavioral measures. For both groups of birds, response rates during the first $5 \mathrm{sec}$ of the test stimulus on positive and negative trials were recorded in the first and second halves of each daily session. From these response rate data, a discrimination index was computed with the following equation: discrimination index $=$ (response rate on positive trials) $\div$ (response rate on positive trials + response rate on negative trials) $\times 100$. A discrimination index of 50 indicates indiscriminate performance. As discriminative performance improves, the index approaches 100.

\section{Results and Discussion}

Figure 1 shows the discrimination index data for Groups CL and LC as a function of training blocks (four 4-day blocks) and session half (first or second).

Discriminative performance for Group CL improved steadily over the four blocks of training. However, performance for Group LC remained near chance levels. These conclusions were supported by the results of an analysis of variance with two repeated measures (blocks and session half), one between-groups measure (stimulus order), and four subject replications per group. This analysis showed that the main effects of groups and of blocks of training, as well as the Groups by Blocks interaction were significant $[\mathrm{F}(1,6)=30.93, \mathrm{~F}(3,18)=$ 11.50 , and $\mathrm{F}(3,18)=9.22$, respectively; ps $<.001]$. Follow-up tests on the interaction indicated that discriminative performance for Group CL changed significantly over the four blocks of training $[F(3,18)=20.66$, $\mathrm{p}<.01]$, but the performance of Group LC did not change $[\mathrm{F}(3,18)<1.0]$.

The primary effect of successive-matching training was on negative color/line trials. For Group CL, mean response rates on negative trials decreased with training, whereas mean response rates on positive trials showed only a small increase. Group LC showed a clear increase in response rates over blocks of training for both positive

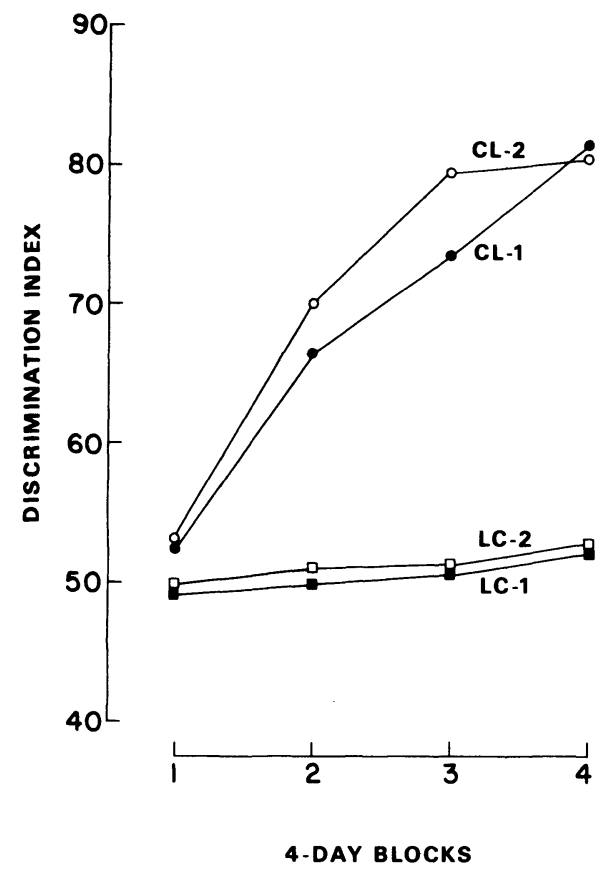

Figure 1. Mean discrimination indexes for color/line (CL) and line/color (LC) groups as a function of session halves (1 or 2) and blocks of training (four 4-day blocks) in Experiment 1.

and negative trials. Only one subject in Group LC showed some evidence of discrimination; the highest level of discriminative performance for this bird was an index of 58.67 in Block 4.

The effect of session half and the Blocks by Session Half interaction were also significant $[F(1,6)=6.23$ and $F(3,18)=3.70$, respectively; ps $<.05]$. As shown in Figure 1, there was a trend for Group CL but not Group LC to perform better in the second half of an experimental session than in the first half, supported by a marginally significant Group by Session Half interaction $[F(1,6)=5.25, p=.062]$. The trend was most evident in Blocks 2 and 3 , in which discriminative performance for Group CL was improving. However, the higher order Group by Block by Session Half interaction was nonsignificant $[F(3,18)=1.55, p=.237]$. In Block 4, the mean CL discrimination indexes for the first and second session halves were 80.21 and 79.47, respectively. Thus, once performance was highly discriminative, the first and second halves of the session tended not to differ.

\section{EXPERIMENT 2}

Experiment 1 confirmed that color/line and line/color problems were learned at unequal rates in the delayedmatching procedure of Konorski (1959). Experiment 2 sought further evidence of the color/line vs. line/color asymmetry by using a within-subjects design. Concurrent scheduling of both problems might facilitate learning the line/color problem, perhaps through bidirectional 
conditioning (Asratyan, 1965). The second experiment also increased both the number of trials per session and the number of sessions. In addition, Experiment 2 studied the effect of three retention intervals, scheduled from the inception of training. Finally, discrimination performance was examined after illuminated and unilluminated retention intervals: conditions that were also programmed from the inception of training. Illumination may produce retroactive interference effects on delayedmatching performance (Roberts \& Grant, 1978). Indeed, it has been conjectured that such retroactive interference may be greater after line samples than after color samples (Farthing et al., 1977).

\section{Method}

Subjects. Four experimentally naive domestic pigeons served. They were housed and maintained as the birds in Experiment 1 were. Prior to experimental training, the subjects were autoshaped to peck the color and line-tilt stimuli described below.

Apparatus. The apparatus was virtually the same as that in Experiment 1. The essential difference was the task stimuli: orange $(\mathrm{O})$, green $(\mathrm{G})$, vertical $(\mathrm{V})$, and horizontal $(\mathrm{H})$ keylights were used.

Procedure. Experimental training involved both color/line and line/color stimulus sequences. The following sequences were designated positive trials: $\mathrm{O}-\mathrm{V}, \mathrm{V}-\mathrm{O}, \mathrm{G}-\mathrm{H}$, and $\mathrm{H}-\mathrm{G}$. The other four possible stimulus sequences were designated negative trials: $\mathrm{O}-\mathrm{H}, \mathrm{H}-\mathrm{O}, \mathrm{G}-\mathrm{V}$, and V-G. The houselight was illuminated throughout an experimental session, except as noted below.

All trials followed a 15 -sec ITI. In the last $2 \mathrm{sec}$ of the ITI, the houselight was pulsed twice (.5 sec off, $.5 \mathrm{sec}$ on) to signal the beginning of a trial. Following the pulsing houselight, one of the four task stimuli appeared on the center key as the sample stimulus. The first peck to the lighted key after $4 \mathrm{sec}$ terminated the sample stimulus and equiprobably initiated a 1-, 4-, or 16-sec retention interval. Following the retention interval, the center key was again illuminated, with one of the four task stimuli constituting the test stimulus. If the sample was a color, then a line appeared as the test stimulus; if the sample was a line, then a color appeared as the test stimulus. Each of the four task stimuli appeared with equal probability as sample and test.

On positive trials, the first peck to the test stimulus after $6 \mathrm{sec}$ terminated the keylight and houselight and initiated a period of reinforcement. On two-thirds of the positive trials, the reinforcement consisted of $2 \mathrm{sec}$ access to the lighted grain hopper. On the remaining positive trials, the hopper was raised for only $.5 \mathrm{sec}$, with an additional $1.5 \mathrm{sec}$ spent in darkness. This permitted more trials per session without satiation effects. On negative trials, the keylight and houselight terminated automatically after $6 \mathrm{sec}$, resulting in a 2 -sec blackout.

One additional variable that was manipulated within the experimental sessions was the presence or absence of the houselight during a retention interval. With a probability of .5 , the houselight remained on during a retention interval ("houselighton" trials). On the remaining trials, the sample and the houselight terminated simultaneously to initiate the retention interval; following the retention interval on these "houselight-off" trials, the test stimulus and the houselight were illuminated simultaneously.

The subjects received 144 daily trials for 48 days of experimental training.

\section{Results and Discussion}

Discriminative performance during the 48 days of experimental training improved from a mean overall

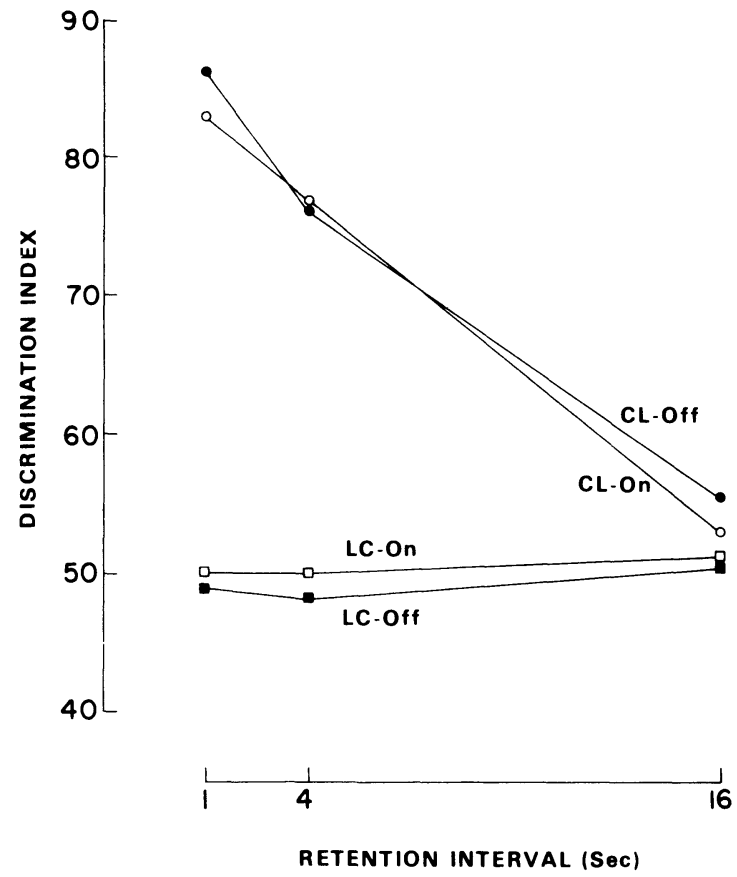

Figure 2. Mean discrimination indexes for color/line (CL) and line/color (LC) trial sequences as a function of the presence or absence of a delay houselight (on or off) and retention interval $(1,4$, or $16 \mathrm{sec})$. The data were averaged over the last 16 days of training in Experiment 2.

discrimination index of 50.00 on Day 1 to a mean overall discrimination index of 61.55 on Day 48. Performance over the last 16 days of training was generally stable. An analysis of variance with three repeated measures (stimulus order, retention interval houselight, and retention interval) and four subject replications was used to assess the discrimination index data pooled for each subject over the last 16 days of training.

In Figure 2, the mean discrimination indexes for terminal performance are shown as a function of stimulus order (CL vs. LC), retention interval houselight (on vs. off), and retention interval $(1,4$, or $16 \mathrm{sec}$ ). The main effects of stimulus order and of retention interval, as well as the Stimulus Order by Retention Interval interaction, were significant $[\mathrm{F}(1,3)=17.43$, $F(2,6)=24.27$, and $F(2,6)=23.42$, respectively; ps $<.025]$. Follow-up tests on the simple main effects of stimulus order indicated a significant effect of retention interval for $\mathrm{CL}$ trials $[\mathrm{F}(2,6)=53.23, \mathrm{p}<.01]$, but not for $\mathrm{LC}$ trials $[\mathrm{F}(2,6)<1.0]$.

The main effect of retention interval houselight and the Houselight by Interval and Houselight by Interval by Stimulus Order interactions were not significant ( $F<1.0$ in all cases). However, the Houselight by Stimulus Order interaction was significant $[F(1,3)=$ 20.63, $p=.02$ ]. For LC trials, the mean discrimination indexes for houselight-off vs. houselight-on conditions 
were 49.12 and 50.30 , respectively; for CL trials, the mean discrimination indexes for houselight-off vs. houselight-on were 72.72 and 70.74 , respectively. For neither stimulus order were the simple main effects of retention interval illumination significant $[F(1,3)=1.31$ for CL trials and .47 for LC trials; $p s>.05]$. It can thus be concluded that houselight illumination during the retention interval did not have a reliable retroactive interference effect on discriminative test performance.

\section{GENERAL DISCUSSION}

The main results of the present pair of experiments can be summarized as follows: (1) Delayed symbolic matching was acquired when the sample stimuli were different key colors and the test stimuli were different line orientations; however, little or no discriminative test responding emerged when the sample and test stimulus assignments were reversed (Experiments 1 and 2). (2) This learning asymmetry resulted both when the two stimulus assignments were given to different groups of subjects (Experiment 1) and when individual subjects received each assignment within daily sessions (Experiment 2). (3) Control over test responding by prior sample stimuli in the color/line problem was a negative function of the retention interval (Experiment 2). And (4) discriminative performance in neither the color/line nor the line/color problem was much affected by house illumination during the retention interval (Experiment 2).

What accounts for the asymmetry in pigeons' learning delayed discriminations of the color/line and line/color varieties? One possible contributing factor that can be convincingly dismissed is that the line-orientation stimuli were exceedingly difficult for the pigeons to discriminate. If this were true, then the learning of even the color/line problem should have been slow and erratic; instead, the results of Experiment 1 showed that such learning was rapid and orderly. In addition to these data, the results of terminal performance in Experiment 2 disclosed that individual subjects accurately discriminated the line orientations when they appeared as test stimuli in the color/line problem, wat the subjects were not at all controlled by the same stiris syisen they appeared as samples in the line/color problem. Even $\operatorname{sisin}_{\mathrm{i}}$ that the present line-orientation stimuli were more difficult to discriminate than the present color stimuli still leaves the within-subjects findings unexplained.

A second hypothesis is that line-orientation stimuli are more susceptible to retroactive interference from house illumination than are color stimuli. However, Experiment 2 failed to reveal any reliable effect of house illumination on either line/color or color/line performance. Here, it might be argued that retroactive interference is not to be expected from house illumination when it is a regular feature of experimental training (cf. Tranberg \& Rilling, 1980). Nonetheless, this objection must acknowledge that house illumination was a constant feature of Experiment 1, and still the color/line problem was learned more rapidly than the line/color problem.

Without denying that line-orientation stimuli may be less discriminable than color stimuli or even more susceptible to retroactive interference, we believe that there may be more plausible explanations. For example, line-orientation stimuli may simply be more poorly remembered by pigeons than are color stimuli (see Farthing et al., 1977). This memory hypothesis has also been proposed to explain poorer delayed-matching performance in rats given visual vs. auditory sample stimuli (Wallace, Steinert, Scobie, \& Spear, 1980).

Another related notion is that poorer delayed-matching performance in the line/color problem than in the color/line problem is due to differential retrieval failure, not to memory loss (Spear, 1978). This view implies that lines may be more effective retrieval cues than colors are. Although there is no intuitive basis for this claim, the retrieval failure hypothesis is both theoretically and empirically distinguishable from the memory loss interpretation. If both lines and colors were to serve as samples and cues from a third dimension were to serve as test stimuli in delayed-matching problems, then only the memory loss hypothesis would expect differential performance, because the retrieval cues for both sets of sample stimuli would be the same.

Further possibilities no doubt exist, and we readily admit that we are still some distance away from comprehending the $C L$ vs. $L C$ asymmetry. However, we feel that the present research progresses toward that goal. First, this work eliminates two prominent explanations of the asymmetry: namely, (1) the pigeon's failure to discriminate line-tilt stimuli and (2) differential retroactive interference from house illumination. Second, the demonstration of stimulus asymmetry is extended to the Konorski (1959) successive-matching procedure. Because this procedure involves only one stimulus at a time being presented as a sample or a test, the observed asymmetry cannot be due to complex interaction effects that may occur if multiple-choice tests are conducted. Although some may judge the present asymmetry to be an isolated peculiarity, we suggest that explicating this and related asymmetries (e.g., Wallace et al., 1980) may bring us much closer to understanding memory processes in animals.

\section{REFERENCES}

Asratyan, E. A. Compensatory adaptations, reflex activity, and the brain. Oxford: Pergamon Press, 1965.

Carter, D. E., \& Eckerman, D. A. Symbolic matching by pigeons: Rate of learning complex discriminations predicted from simple discriminations. Science, 1975, 187, 662-664.

Carter, D. E., \& Werner, T. J. Complex learning and information processing by pigeons: A critical analysis. Journal of the Experimental Analysis of Behavior, 1978, 29, 565-601.

Farthing, G. W., Wagner, J. M., Gilmour, S., \& Waxman, H. M. Short-term memory and information processing in pigeons. Learning and Motivation, 1977, 8, 520-532.

Honig, W. K., \& Wasse rman, E. A. Performance of pigeons on delayed simple and conditional discriminations under equivalent training procedures. Learning and Motivation, 1981, 12, 149-170.

Konorsk1, J. A new method of physiological investigation of recent memory in animals. Bulletin de l'Academie Polonaise des Sciences, Serie des Sciences Biologiques, 1959, 7, 115-117.

Roberts, W. A., \& Grant, D. S. An analysis of light-induced retroactive inhibition in pigeon short-term memory. Journal of Experimental Psychology: Animal Behavior Processes, 1978, 4, 219-236.

SPEAR, N. E. The processing of memories: Forgetting and retention. Hillsdale, N.J: Erlbaum, 1978.

Sutherland, N. S., \& Mackintosh, N. J. Mechanisms of animal discrimination learning. New York: Academic Press, 1971.

Tranberg, D. K., \& Rilling, M. Delay-interval illumination changes interfere with pigeon short-term memory. Journal of the Experimental Analysis of Behavior, 1980, 33, 39-49.

Wallace, J., Steinert, P. A., Scobie, S. R., \& Spear, N. E. Stimulus modality and short-term memory in rats. Animal Learning \& Behavior, 1980, 8, 10-16.

(Received for publication July 14, 1981.) 